the presence of atypical lymphocytes in the peripheral bloodhave already been described and the findings of previous authors are reviewed. Attention is drawn to the presence of lymphadenopathy, which appears to occur more often than suggested by earlier reports. A transient rubelliform rash was noted in four of the nine patients-a previously unrecorded manifestation of the illness.

Awareness of the syndrome may prevent unwarranted investigation or treatment for subacute bacterial endocarditis.

Although the aetiology is uncertain, it is suggested that it is most reasonable to regard the syndrome as a viral disease closely related to infectious mononucleosis and that it is transmitted by blood transfusion.

I wish to thank Mr. H. H. Bentall, Mr. W. P. Cleland, Professor J. F. Goodwin, and Dr. D. Melrose for permission to publish details of their cases and for helpful criticism.

\section{REFERENCES}

Anderson, R., and Larsson, O. (1963). Lancet, 2, 947.

Bang, J. (1943). Acta med. scand., 113, 304.

de Vos, J. F., and Kuipers, F. H. (1951). Ned. T. Geneesk., 95, 3036.

Downey, H., and McKinlay, C. A. (1923). Arch. intern. Med., 32, 82.

Evans, A. S. (1960). Amer. F. Hyg., 71, 342.

Hobson, F. G., Lawson, B., and Wigfield, M. (1958). Brit. med. F., 1, 845 .

Holswade, G. R., Engle, M. A., Redo, S. F., Goldsmith, E. I., and Barondess, J. A. (1963). Circulation, 27, 812.

Kreel, I., Zaroff, L. I., Canter, J. W., Krasna, I., and Baronofsky, I. D. (1960). Surg. Gynec. Obstet., 111, 317.

Leibowitz, S. (1953). Infectious Mononucleosis. Grune and Stratton, New York.

Perillie, P. E., and Glenn, W. W. L. (1962). Yale 7. Biol. Med., 34, 625. Pfeiffer, E. (1889). $7 b$. Kinderheilk., 29, 257.

Seaman, A. J., and Starr, A. (1962). Clin. Res., 10, 104.

Shubert, S., Collee, J. G., and Smith, B. J. (1954). Brit. med. 7., 1, 671.

Wheeler, E. O., Turner, J. D., and Scannell, J. G. (1962). New Engl. f. Med., 266, 454.

Wising, P. J. (1942). Acta med. scand., 109, 507.

\title{
Myocardial Infarction-like Syndrome in Cholecystectomized Patients Given Narcotics
}

\author{
SANFORD M. MOSSBERG,* M.D.
}

\author{
Brit. med. F., 1964, 1, 948-950
}

Morphine, codeine, and pethidine (meperidine, U.S.P.) are known to produce contraction of the sphincter of Oddi, elevation of intrabiliary pressure, and pain in the chest or abdomen (Gaensler, McGowan, and Henderson, 1948 ; Curreri and Gale, 1950). Although hyperamylasaemia can follow narcotic administration in normal individuals (Bogoch, Roth, and Bockus, 1954), a narcotic-induced rise of serum glutamic oxaloacetic transaminase (S.G.O.T.) activity occurs chiefly in patients with cholecystectomy or non-functioning gall-bladder (Mossberg, Bloom, Berkowitz, and Ross, 1962) Electrocardiographic changes, too, can result from increased intrabiliary pressure (Clarke, 1945).

This report describes the cases of three patients in whom the combination of chest pain, electrocardiographic abnormalities, and an elevated transaminase level was responsible for the erroneous initial impression of myocardial infarction. Recurrent elevations of transaminase activity following narcotics, a history of cholecystectomy, and absence of progression of a typical infarct pattern on the electrocardiogram all led to the recognition that myocardial infarction was being simulated by biliarytract factors.

\section{Case 1}

A 68-year-old white housewife was admitted to Montefiore Hospital on 26 May 1958 complaining of substernal and leftupper-quadrant-pressure pains occurring intermittently for three weeks. The pains were unrelated to meals or exercise, would last from one to three hours, and could not be relieved by nitroglycerin.

Past medical history included tuberculosis and typhoid fever during childhood, acute rheumatic fever in 1933, cholecystectomy for cholelithiasis in 1950, probable myocardial infarction and gastric ulcer in 1954, duodenal ulcer in 1955, and mild congestive heart failure since 1956. Digoxin and chlorothiazide had given moderately good control of cardiac symptoms and signs, although during the week prior to admission she had noted increased exertional dyspnoea.

\footnotetext{
* From the Department of Gastroenterology, Division of Medicine,
} Montefiore Hospital, New York, New York, U.S.A.
Because of continuous substernal pain, pethidine, $50 \mathrm{mg}$, was administered intramuscularly six hours before admission.

Physical examination revealed a thin white woman who appeared alert and younger than her stated age. Blood-pressure was $140 / 74$, pulse $68 / \mathrm{min}$., respirations $16 / \mathrm{min}$., and temperature $101^{\circ} \mathrm{F}$ $\left(38.3^{\circ}\right.$ C.). There was no neck-vein distension. The anteroposterior diameter of the chest cage was increased but no adventitious sounds were heard. The cardiac apex impulse was in the sixth intercostal space between the midclavicular and anterior axillary lines. A grade 2 harsh apical systolic murmur radiated to the left axilla and lower left sternal border. No diastolic murmur was heard. The second heart sound was booming over the aortic area and split over the pulmonic area. A gallop was not present. The abdomen was soft with no organ enlargement, and there was slight tenderness in the left upper quadrant. A cholecystectomy scar was present. Moderate pitting oedema extended from the ankles to the mid-leg.

Blood examination on admission showed: haematocrit $34 \%$, white blood count and differential normal, sedimentation rate $29 \mathrm{~mm}$./hour (Wintrobe), blood sugar $75 \mathrm{mg} . / 100 \mathrm{ml}$., blood urea nitrogen $15 \mathrm{mg} . / 100 \mathrm{ml}$., normal electrolytes, and S.G.O.T. 176 units (upper normal limit 38 units). Venous pressure was $60 \mathrm{~cm}$. citrate and circulation time (dehydrocholate) 15 seconds. The electrocardiogram (Fig. 1) revealed changes which were interpreted as representing a possible myocardial infarct of the posterior wall of indeterminate age. The patient was placed on a coronary regimen, but no anticoagulants were given. On 28 May alkaline phosphatase, cephalin flocculation, and thymol turbidity were normal. On 29 May, because of shortness of breath, oxygen by nasal catheter and morphine sulphate, $8 \mathrm{mg}$., were given at $2 \mathrm{p} . \mathrm{m}$. Blood taken at 7 a.m. the next day showed an S.G.O.T. activity of 976 units (checked for accuracy). No clinical change had taken place and the patient continued to progress satisfactorily. On 1 June pethidine, $75 \mathrm{mg}$., was given parenterally during an episode of epigastric distress, and on the following day the S.G.O.T. activity was 90 units. The possibility of extension of an infarct was considered. Upon review of the chart, however, it became apparent that no significant change had occurred in the electrocardiogram and that transaminase elevations were probably related to narcotic administration. The patient was progressively ambulated. On 23 June an episode of chest and abdominal pain was treated with barbiturates rather than with narcotics. No further S.G.O.T. rise 
was noted. Upper gastro-intestinal $x$-ray films on 16 July revealed a deformed duodenal bulb. The patient was discharged on 13 August. A subsequent intravenous cholangiogram revealed a prominent cystic duct stump.

\section{Case 2}

A white plumbing contractor aged 52 was admitted to Montefiore Hospital on 14 February 1960 with chest pain of 18 hours' duration. Since 1952 he had had intermittent episodes of angina pectoris after exertion and relieved by rest or nitroglycerin. There was no history of cough, fever, dyspnoea, orthopnoea, or ankle-swelling. On the evening prior to admission, shortly after eating supper, he experienced midsubsternal chest pain which was relieved partially by nitroglycerin and completely by belching. The pain was recurrent and colicky. On the following afternoon (14 February) he visited his family physician and because of an abnormal electrocardiogram was admitted to Montefiore Hospital.

Past history revealed cholecystectomy in 1952 for cholecystitis, cholelithiasis, and choledocholithiasis.

Physical examination showed an obese white man in mild respiratory distress. Blood-pressure was $110 / 70$, pulse 100 , respirations 30 , and temperature $101.4^{\circ} \mathrm{F} .\left(38.6^{\circ} \mathrm{C}\right.$.). Slight pharyngeal redness was noted. Neck veins were not engorged. Decreased breath sounds and crepitant rales were heard over the right lower lobe. The heart was enlarged to the left on percussion. Rhythm was regular and a distinct protodiastolic gallop was heard over the praecordium. No murmur was noted. Abdominal examination was negative and peripheral oedema was absent.

On admission the haemogram showed: hematocrit $47 \%$, white blood count $8,600 /$ c.mm. (poly $83 \%$, bands $10 \%$, lymphocytes $6 \%$, metamyelocytes $1 \%$ ). Sedimentation rate (Wintrobe) was $35 \mathrm{~mm}$./ hr., and blood urea nitrogen $24 \mathrm{mg} . / 100 \mathrm{ml}$; normal. S.G.O.T. was 24 units. An electrocardiogram (Fig. 2) revealed widespread ST-T-wave changes suggestive of myocardial ischaemia. Chest $x$-ray examination showed cardiomegaly, engorgement of pulmonary vessels, and a zone of increased density in the right mid-lung field. Treatment was begun with oxygen, pethidine, warfarin, and digitalization. Chest pain continued and temperature rose to $103^{\circ} \mathrm{F} .\left(39.4^{\circ} \mathrm{C}\right.$.). Tetracycline and chloramphenicol were

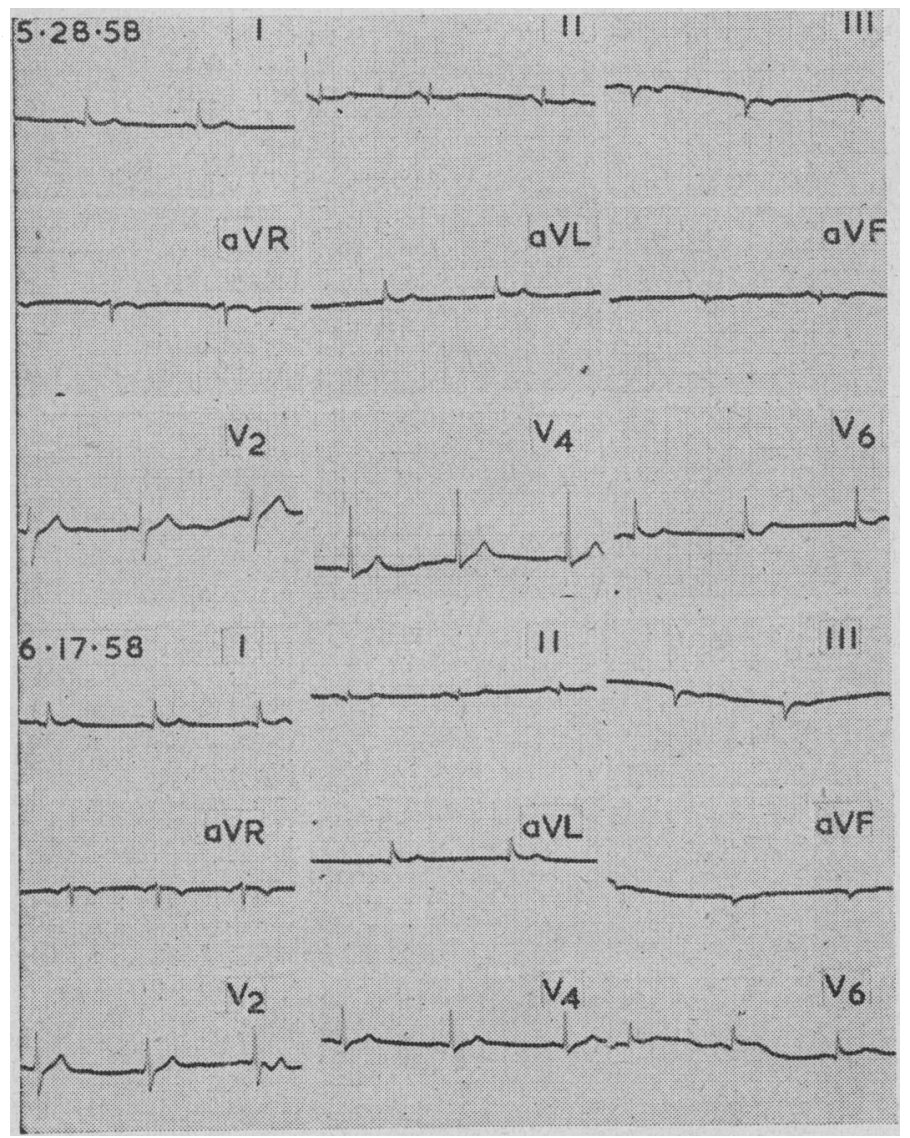

FIG. 1.-E.C.G. findings in Case 1. started. On 15 February the S.G.O.T. level was 540 units. Because of recurrent chest pain pethidine was required on 15 and 16 February. On 17 February the S.G.O.T. activity was 535 units. Over the next three weeks improvement occurred with disappearance of pain, gradual defervescence of fever, and clearing of the pneumonitis. No significant change in the contour of the electrocardiogram occurred.

On 4 March the patient was given pethidine, $100 \mathrm{mg}$. intramuscularly, in an effort to provoke elevation of S.G.O.T. activity. Sixteen hours after narcotic administration the S.G.O.T. level was 237 units. The patient was discharged on 22 March with a final diagnosis of pneumonitis and arteriosclerotic cardiovascular disease.

\section{Case 3}

A white taxicab driver aged 48 was admitted to Montefiore Hospital on 11 June 1960 with a one-week history of chest pain. On 4 June, while sitting in a chair, he experienced gradual onset of dull, "drawing," midsubsternal chest pain radiating through to the interscapular area. A feeling of heaviness was noted in both shoulders, but he had no dyspnoea, sweating, or nausea. The pain lasted for six hours and disappeared spontaneously. Similar pain recurred on the morning of 11 June, and the patient presented himself at the Montefiore Hospital emergency room, where an electrocardiogram revealed a sinus rhythm at rate 100 with ST-T depressions in V 2-4 and $\mathrm{T}$-wave inversions in leads $1, \mathrm{aVL}$, and $\mathrm{V} 2-6$. He was admitted with a diagnosis of myocardial infarction of the anterior wall.

Prior illnesses included intermittent hypertension and cholecystectomy in 1947 for cholelithiasis and "drawing" pains in the lower chest.

Physical examination revealed a middle-aged white man, moderately anxious, but in no acute distress. Blood-pressure was $160 / 100$, pulse 80 , respirations 20 , and temperature $98.6^{\circ} \mathrm{F}$. $\left(37^{\circ} \mathrm{C}\right.$.). Neck veins were flat and the lungs were clear. The cardiac apex impulse was in the fifth intercostal space medial to the midclavicular line. A regular rhythm was present and heart sounds were of good intensity with no murmur, rub, or gallop. Abdominal examination

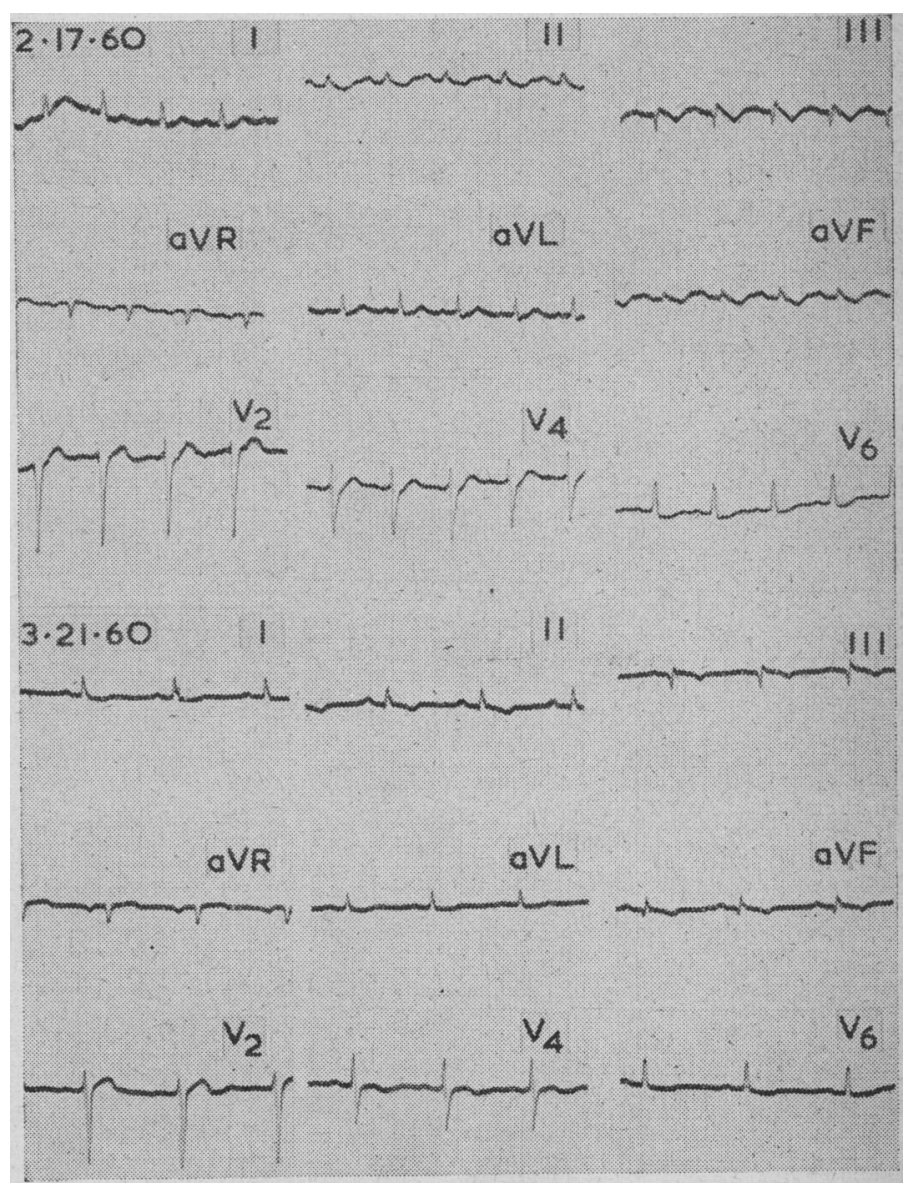

FIG. 2.-E.C.G. findings in Case 2. 
revealed a cholecystectomy scar, no organ enlargement, and mild epigastric tenderness. There was no peripheral oedema.

Laboratory tests showed: haematocrit $46 \%$, white blood count $11,200 /$ c.mm. (mature polys $82 \%$, band forms $7 \%$, lymphocytes $11 \%$ ). Blood sugar, blood urea nitrogen, amylase, cholesterol, alkaline phosphatase, and prothrombin time were all normal. S.G.O.T. was 39 units. Anticoagulation was begun with warfarin. On the evening of 12 June, because of inability to sleep, the patient was given codeine sulphate $32 \mathrm{mg}$. intramuscularly. Eight hours later the S.G.O.T. activity was 63 units, and this was interpreted as confirming the presence of a myocardial infarct. He continued to do well clinically. On 16 June he complained of heartburn, and codeine sulphate, $32 \mathrm{mg}$., was given orally. The next morning his S.G.O.T. level was 343 units, and extension of a myocardial infarct was postulated. On reviewing the case it was suspected that since there had been no significant change in the electrocardiographic pattern, the transaminase elevations might have been caused by narcotic administration. On 23 June a provocative dose of codeine sulphate, $32 \mathrm{mg}$., was given intramuscularly, and next day the S.G.O.T. activity was 116 units. The patient continued to have an uneventful course and was discharged on 2 July.

The relation between S.G.O.T. elevations and narcotic administration is summarized for all patients in the Table.

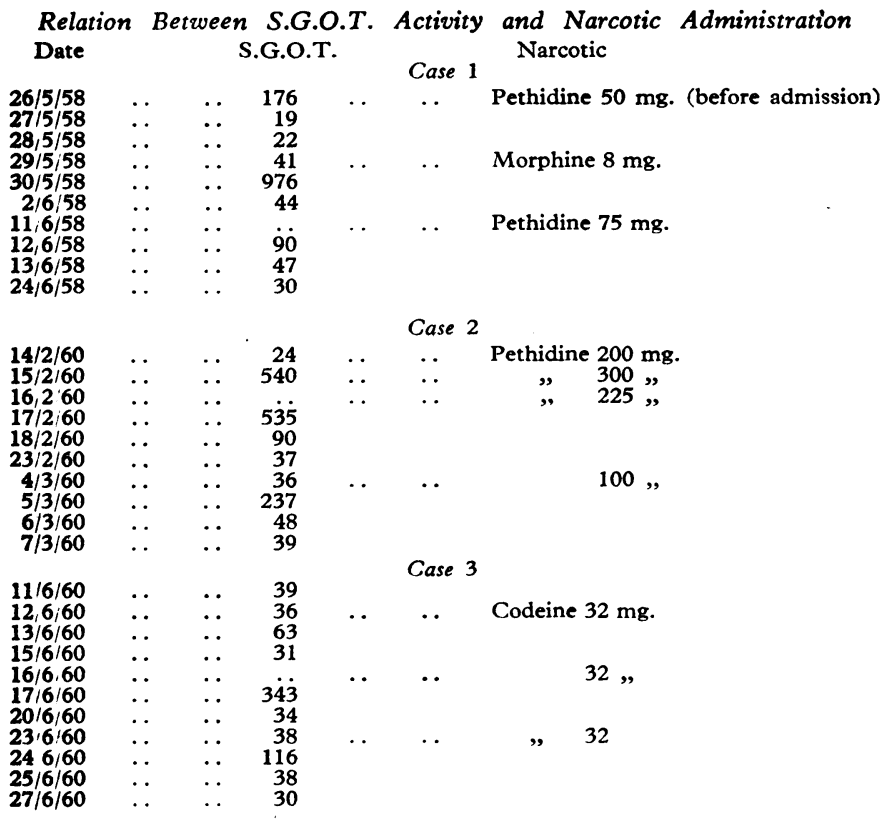

\section{Discussion}

In each case an initial diagnosis of myocardial infarction was based on the presence of concomitant electrocardiographic abnormalities and increased S.G.O.T. activity. Although coronary artery disease may have been present in all patients, in none were there serial electrocardiographic changes diagnostic of acute myocardial infarction. In two cases subsequent elevations of S.G.O.T. activity were explained on the basis of " extension of the infarct." Recognition, however, that rises in transaminase activity were associated with narcotic administration, a stable electrocardiogram, and a past history of cholecystectomy led to the performance of provocative enzyme tests. Transaminase elevations after test doses of narcotics in the two cases studied confirmed the presence of S.G.O.T. sensitivity to narcotic administration. Factors such as shock and rightsided congestive heart failure were not related to enzyme Increments.

Although pathological data were not available in these cases, the occurrence of S.G.O.T. activity in excess of 300 units in relation to uncomplicated extrahepatic biliary obstruction has been documented (Mossberg and Ross, 1963). Particularly interesting was the case of a 54-year-old white man (Mossberg and Ross, 1963) admitted because of substernal pain, a high transaminase level, and electrocardiographic changes suggesting acute coronary ischaemia. He was treated with the usual coronary regimen, and his hospital course was complicated by several transaminase spikes attributed to "extension of the infarct." A subsequent cholecystogram revealed multiple gallstones. After cholecystectomy the patient died of acute bacterial endocarditis. Post-mortem examination revealed no evidence of myocardial infarction.

Electrocardiographic changes resulting from increased intrabiliary pressure are caused by a reduction in coronary artery blood-flow mediated through the vagus nerve (Cullen and Reese, 1952). The patient with pre-existing coronary artery disease, therefore, would be more susceptible to the effects of reduced blood-flow to the heart.

Elevation of S.G.O.T. activity following narcotic administration occurs only in an individual with cholecystectomy or nonfunctioning gall-bladder, (Mossberg et al., 1962). The mechanism is probably similar to narcotic-induced elevation of amylase activity. In the normal pancreatic ductal system increased pressure is transmitted direct to the acini, and it is not unusual to find hyperamylasaemia after narcotics, especially if the pancreas is actively secreting. The normal biliary tract, however, contains the gall-bladder, an organ which mitigates increased intrabiliary pressure by expanding in size and by removing water. If no gall-bladder is present, elevated intraductal pressure is transmitted direct to the liver cells and increased S.G.O.T. activity becomes evident, most likely as a result of altered cellular permeability and leakage of enzyme through anatomically intact liver cells (Mossberg and Ross, 1963).

It is thus evident that when myocardial infarction is suspected, elevated S.G.O.T. levels must be interpreted with caution in patients with cholecystectomy, prior narcotic administration, and equivocal electrocardiographic changes. A concomitant increase of alkaline phosphatase activity should suggest the presence of biliary-tract factors (Mossberg et al., 1962).

\section{Summary and Conclusions}

Differentiation between biliary-tract and myocardial disease is often difficult. Three cases are reported in which the combination of electrocardiographic abnormalities and elevated serum transaminase activity prompted an erroneous initial diagnosis of myocardial infarction. Two of the patients had subsequent spikes of S.G.O.T. activity which were attributed to " extension of the infarct." Knowledge of prior cholecystectomy, failure to find progressive change in the electrocardiogram, and recognition that each rise in enzyme activity was preceded by narcotic administration led to the suspicion that biliary-tract factors might be causing the abnormalities. This impression was documented in two patients by observing significant elevations in S.G.O.T. activity after the provocative administration of narcotics.

Cholecystectomized patients are particularly sensitive to narcotic-induced spasm of the sphincter of Oddi, and it is postulated that elevated intrabiliary pressure in such individuals is transmitted direct to the hepatic cell, causing liberation of transaminase into the blood-stream.

It is concluded that in a cholecystectomized patient who has received narcotics and in whom the electrocardiogram is unchanging one should not necessarily relate increased serum transaminase activity to myocardial necrosis.

\section{REFERENCES}

Bogoch, A., Roth, J. L. A., and Bockus, H. L. (1954). Gastroenterology, 26, 697.

Clarke, N. E. (1945). Amer. Heart f., 29, 628.

Cullen, M. L., and Reese, H. L. (1952). F. appl. Physiol., 5, 281.

Curreri, A. R., and Gale, J. W. (1950). Ann. Surg., 132, 348.

Gaensler, E. A., McGowan, J. M., and Henderson, F. F. (1948). Surgery, 23, 211.

Mossberg, S. M., Bloom, A., Berkowitz, J., and Ross, G. (1962). Arch.

intern. Med., 109, 429. 